\title{
Meshplasty treatment for stress urinary: a prospective clinical trial
}

\author{
Pramila Yadav*, Rajendrasaraogi, Komal N. Chavan
}

Department of Obstetrics and Gynecology, Dr. R. N. Cooper Hospital, Mumbai, India

Received: 25 January 2017

Revised: 01 February 2017

Accepted: 02 March 2017

\author{
*Correspondence: \\ Dr. Pramila Yadav, \\ E-mail: pramila411@gmail.com
}

Copyright: ( the author(s), publisher and licensee Medip Academy. This is an open-access article distributed under the terms of the Creative Commons Attribution Non-Commercial License, which permits unrestricted non-commercial use, distribution, and reproduction in any medium, provided the original work is properly cited.

\section{ABSTRACT}

Background: Stress urinary incontinence is when there is involuntary loss of urine due to increase intra-abdominal and intravesical pressure.

Methods: This is a prospective clinical trial which was conducted at a Municipal General Hospital in Mumbai in the Department of Obstetrics and Gynecology for a period of 10 years from January 2005 to December 2015.The study group consisted of 518 cases with clinically demonstrable SUI with or without pelvic floor defects. Meshplasty was performed as a choice of surgery for SUI correction.

Results: The study group was divided based on age(25-40,41-55,>55),parity(I,II-III,>IV), symptoms (SUI, Dysfunctional uterine bleeding, prolapse), type of anaesthesia (local, general/spinal anaesthesia), surgery performed (meshplasty alone, meshplasty with cystorectocele repair, meshplasty with vaginal hysterectomy (VH), meshplasty with $\mathrm{VH}$ with cystorectocele repair, meshplasty with $\mathrm{VH}$ with cystorectocele repair with sacrospinous fixation), complications (mesh rejection, urine retention).

Conclusions: Meshplasty is a simple inexpensive procedure with short learning curve. This has a $94 \%$ success rate.

Keywords: Meshplasty, Polypropylene mesh, Stress urinary incontinence

\section{INTRODUCTION}

Stress urinary incontinence (SUI) is defined as involuntary loss of urine due to increased intra-abdominal and intravesical pressure, which exceeds the pressure that the urethral closure mechanism can withstand and little urinary loss results. ${ }^{1,2}$ Stress incontinence affects $15-60 \%$ of women. Stress incontinence is a disorder of young as well as old people.

More than a quarter of nulliparous, young college, athletes experience stress incontinence while participating in sports. ${ }^{2,3} \mathrm{We}$ have older methods like Kelly's repair and abdominal bladder neck suspension surgeries. The newer techniques are Tension-free vaginal tape (TVT), trans-obturator tape (TOT) and meshplasty. ${ }^{1-4}$

\section{Principle of meshplasty}

Recent advances in the mechanism of SUI show that the support at midurethral level is weak resulting into sagging of midurethra. Whenever intra-abdominal pressure rises while coughing, sneezing, The intravesical and the proximal urethral pressure becomes more than that in the midurethra resulting into dribbling or urine (SUI). ${ }^{2}$ It will be irrational to use this already weak and torn pubovesicocervico vaginal fascia to support the urethra. ${ }^{2}$ It may give temporary relief but not long term success as seen in Kelly's plication suture. Hence these supports should be enhanced and re-established by using synthetic material like polypropylene mesh, to provide a permanent solution. We innovated the technique of meshplasty for SUI correction in which the lost fascial support of mid urethra is re-established by simply fixing the flexible, non-absorbable, non-reactive polypropylene 
mesh (hernia mesh) at midurethral level. The polypropylene mesh provides mechanical support at the place of the torn and detached pubocervicalfascia. ${ }^{3}$ The mesh gets interpenetrated by fibrous tissue, creating a tough scar and so causing permanent support for the midurethra.

\section{METHODS}

This prospective clinical trial was conducted at Municipal General Hospital in Mumbai for a period of 10 years from January 2005 to December 2015 and comprised of 518 cases in which Meshplasty was performed as a choice of surgery for SUI correction.

\section{Inclusion criteria}

- $\quad$ Any age group

- Any parity

- Clinically demonstrable stress urinary incontinence

- With or without associated pelvic floor defect

- Positive Marshal and Bonney's test, and Q-Tip test

\section{Exclusion criteria}

- Urge incontinence

- $\quad$ Urinary tract infections (UTIs)

All the patients should be thoroughly evaluated by detailed history, urogynecological symptoms questionnaire, and complete physical examination. All patients had positive Marshall Test and Bonney test. The cough test is recommended prior to surgery. Urodynamic investigations are not essential prior to surgery provided the clinical assessment is fully comprehensive (standardised questionnaire, cough test, bladder diary, post void residual volume) with concordant results (PC).

In all patients' polypropylene mesh of adequate size is placed loose at midurethral level, extending from one paraurethral gutter to the other.

Written informed consent is taken. Cefotaxim $1 \mathrm{~g}$ intravenously is given to all the patients just prior to the anaesthesia.

\section{Surgical technique}

Meshplasty can be performed under local and spinal anaesthesia in lithotomy position. Injection Saline adrenaline infiltration $(1: 2,00,000)$ is used for local anaesthesia. The indwelling Foley's catheter helps to define the midurethra and location of bladder neck.

Two allies forceps applied at mid urethral. Small vertical incision is taken between two allies' forceps on the vagina. Both side paraurethral spaces are created by mosquito forceps. A polypropylene mesh used in hernia repair measuring approximately $3-4 \mathrm{cmx} 1 \mathrm{~cm}$ is placed at midurethral level. In patients with only SUI, the mesh is kept (no fixation sutures require) in the dissected space at mid urethral level mesh is placed in a tension freeway, so that a small forceps can be easily passed beneath it and vagina was closed above it with vicryl no 3-0. In the patients with only meshplasty, catheter is removed the evening of surgery or the next morning. Patient can be discharged.

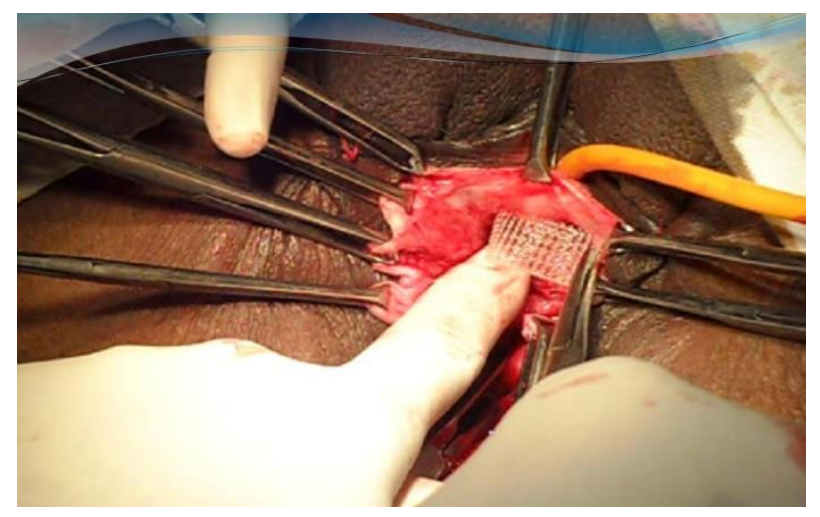

Figure 1: Mesh at midurethral level.

In patients requiring hysterectomy and anterior colporrhaphy, vaginal hysterectomy is performed first, followed by dissection of anterior vaginal wall as is being done in standard anterior colporrhphy (Figure 1). The mesh is fixed laterally by anchoring its angles to the pubocervical fascia along with vagina using polyglatin No.3-0 suture. Mesh is fixed in a tension freeway, so that a small forceps can be easily passed beneath it. After placement of this mesh anterior colporrhaphy is performed. The patients with anterior colporrhaphy, Foley's catheter are removed on Day 3 of surgery.

All patients are checked for residual urinary volume, which is less than $50 \mathrm{~mL}$. At the time of discharge, patients were instructed to avoid strenuous physical activities and sexual inter.

\section{Postoperatively care}

- Patients were ambulated by evening

- Vaginal pack, if kept, was removed the following day

- Antibiotics

The catheter is removed on same day or day three depending on the other ancillary procedures that have been performed and the residual urinary volume is measured. We also looked for any leak with Valsalva'smaneuver. The patients are called at weekly intervals for one month and monthly for 6 month then every 6 monthly till date.

During each weekly visit, a mild vaginal douche is given with hydrogen peroxide and betadine and the process of healing is studied. We look out for signs of mesh 
rejection. During each visit they are questioned regarding recurrence of previous symptoms. The cure of SUI is based on absence of urinary complaints and no urinary leakage with Valsalva's manoeuvre. The criteria for failure of surgery are any patient complaining of recurrence of previous symptoms, or having demonstrable urinary leakage.

\section{Follow up}

- Weekly for 1 month

- During each weekly visit, a mild hydrogen peroxide and betadine vaginal douche was given.

- $\quad$ Pattern of healing was studied.

- $\quad$ Signs of mesh rejection if present were noted

- $\quad$ Followed by once a month till 6 months and

- 6 monthly for 2 years and yearly till date

- $\quad$ Out of 518 cases, 146 patients are lost to follow-up during different intervals. In the remaining 372 cases, follow-up time varied from 1 month to 6yrs.

\section{RESULTS}

In our study we have performed 518 cases in 10 years of period; the maximum number of patient was in age group of $41-55$ i.e. $51.73 \%$ after that $25-40$ years of age group i.e. $37.25 \%$.the commonest after patients were para 2 or more 289 cases i.e. $55.79 \%$.

Table 1: Distribution of cases according to surgical procedure performed.

\begin{tabular}{|ll|}
\hline Surgery & Number \\
\hline Only meshplasty & 205 \\
\hline Cysto-rectocele repair & 74 \\
\hline Vaginal hysterectomy with a-p repair & 114 \\
\hline $\begin{array}{l}\text { Vaginal hysterectomy with a-p repair with } \\
\text { sacrospinous fixation }\end{array}$ & 28 \\
\hline $\begin{array}{l}\text { Vault prolapse repair with sacrospinous } \\
\text { fixation }\end{array}$ & 18 \\
\hline Vaginal hysterectomy & 79 \\
\hline
\end{tabular}

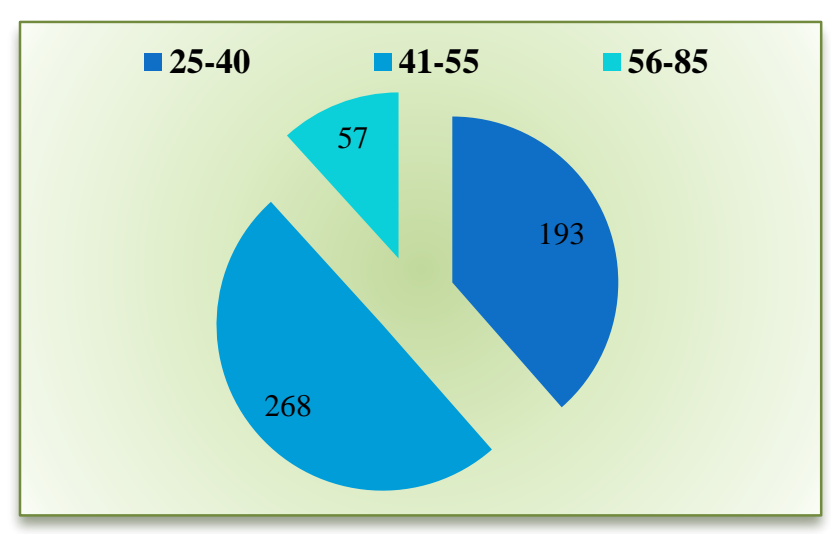

Figure 2: Distribution of cases in relation to age.
Commonest presentation was SCOPV in 286 casas i.e. $55.2 \%$ followed by dysfunctional uterine bleeding 169 cases i.e.55.2\% and 63 patients were presented with only SUI.

Table 2: Complications.

\begin{tabular}{|lll|}
\hline Complications & Cases & Percent \\
\hline Mesh rejection & 22 cases & 4 \\
\hline Retention of urine & 12 cases & 2 \\
\hline
\end{tabular}

Out of 518 cases the maximum cases were done under spinal anaesthesia and 160 cases done under local anaesthesia. We had combined the meshplasty with other major surgeries that's why the maximum cases were done under spinal anaesthesia.

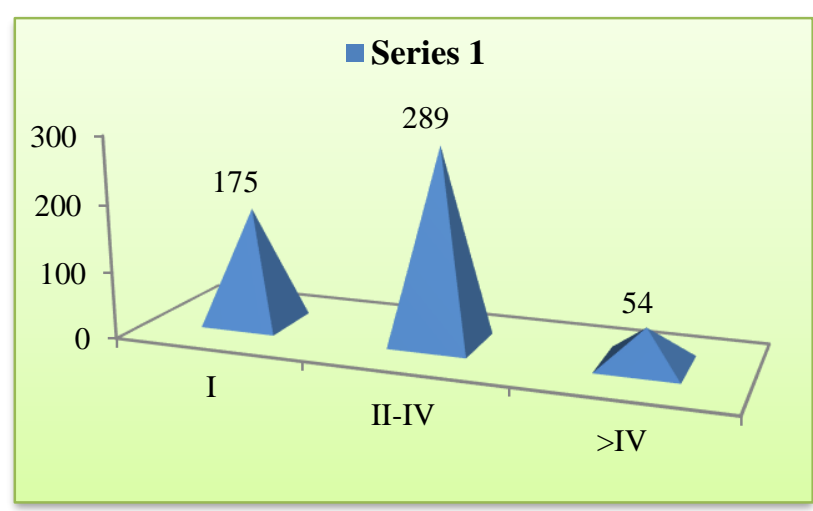

Figure 3: Distribution of cases in relation to parity.

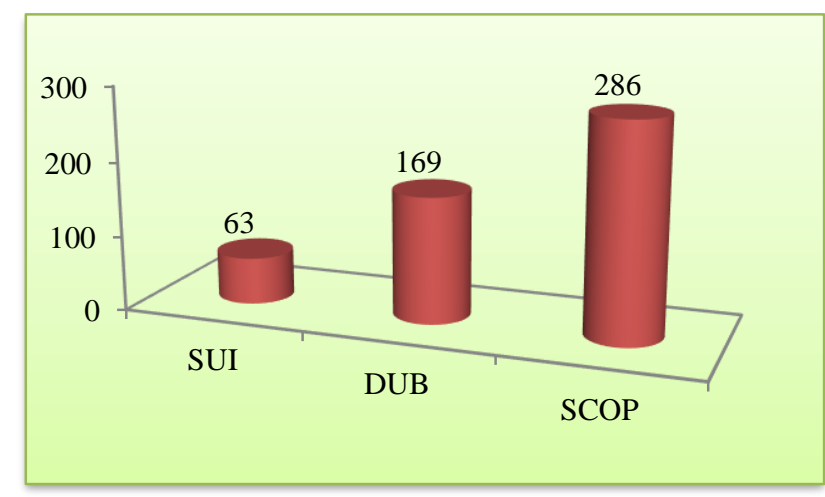

Figure 4: Distribution of cases according to symptoms.

Only meshplasty was performed in 205 cases i.e. $39.57 \%$. Cystorectocele repair in 74 patient's i.e. $14.47 \%$. Vaginal hysterectomy with AP repair was done in 114 cases i.e. $20 \%$.

Vaginal hysterectomy with AP repairs with sacrospinous fixation in 28 cases i.e. 5\%. Vault prolapse repair with sacrospinous fixation was done in 18 cases i.e. $3.4 \%$. Vaginal hysterectomy with meshplasty was done in 79 cases i.e. $15.25 \%$. We had very less complications like 
mesh rejection in 22 cases i.e. $4 \%$ and retention of urine in 12 cases i.e. $2 \%$.

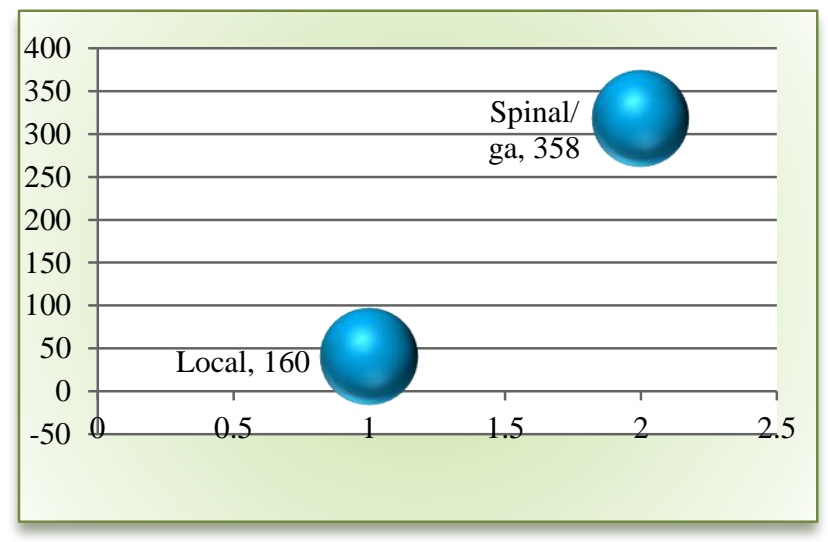

Figure 5: Distribution of cases in relation to type of anaesthesia used.

\section{DISCUSSION}

This prospective clinical trial was conducted at Municipal General Hospital in Mumbai in Dr. R. N. Cooper Hospital for a period of 10 years from January 2005 to December 2015 and comprised of 518 cases in which Meshplasty was performed as a choice of surgery for SUI correction. $^{5,7}$

First case of meshplasty for SUI is performed in 2005 at Dr. R. N. Cooper hospital by Dr. Rajendra M. Saraogi. Meshplasty is a very simple and quick procedure, which can be performed under local anesthesia. It can be performed in patients with medical disorders like hypertension, diabetes, heart disease. It can be performed in remote places where minimum facilities are available. It has a short learning curve. Hospital stays of 1 day or maximum 3 days when other ancillary procedures are performed. It does not require any special skill or any special surgical instrument. Duration of procedure: It is very quick procedure. Isolated meshplasty procedure requires 10-15 minutes. Assistance from other surgical faculties like urology is not required. Intra operative complications: None of these patients had any haemorrhage, injury to bladder, urethra and other existing structure. Postoperative complications like febrile illness, morbidity, local and systemic infection are not seen in any of the patients. Retention of urine was seen in $2 \%$ of cases, which was treated after prolonged catheterization. Mesh rejection was seen in $4 \%$ cases, which were not rejection perse but were erosions under the mesh which was treated with betadine ointment application and oral antibiotic treatment. Success rate: No recurrence has been recorded till date. None have reported with failure, thus giving almost $99 \%$ cure rates for SUI. Cost effectiveness: Mesh plasty is cost effective in comparison to other corrective surgery like sling surgeries (TVT, TOT, TSUIT and retro pubic colpo suspension). Here we used hernia mesh which was cut into $3 \times 1 \mathrm{cms}$. One hernia mesh can be used for at least 10 patients.

\section{CONCLUSION}

We have performed 518 cases in our institutes without any major complication with successes rate of $99 \%$. This preliminary report shows that our innovative procedure of meshplasty is simple, easy to perform, efficient and cost effective. Every gynecologist can do it independently without the help of urologists.

\section{Funding: No funding sources}

Conflict of interest: None declared

Ethical approval: The study was approved by the Institutional Ethics Committee

\section{REFERENCES}

1. Colombo M, Vitobello D, Proietti F. Randomized comparison of burch colposuspension v/s anterior colporrhaphy in women with SUI and anterior vaginal wall prolapse. BJOG 2000;107:544-51.

2. Shawn A, Lewis L. Incontinence, prolapse a disorder of pelvic floor. In, Jonathan S. Berek (Ed), Novak's Gynecology, 13th Edition. New York, Lippincott Williams \& Wilkins 2002;671-2.

3. Lee RA. Vaginal hysterectomy with repair of enterocele, cystocele and rectocele. Clin Obstet Gynecol. 1993;36:967-75.

4. Wall LL. Urinary stress incontinence. In: Rock JA, Thompson JD (eds.), TeLinde's Operative Gynecology, 9th Edition. Philadelphia, Lippincott Williamand Wilkins. 1997:1071.

5. Mansfield DR, Gollogly NC, Kaye DM, Richardson M, Bergin P, Naughton MT. Controlled trial of continuous positive airway pressure in obstructive sleep apnea and heart failure. American Journal of Respiratory and Critical Care Medicine. 2004;169(3):361-6.

6. Winger MJ, Macdonald DR, Cairncross JG. Supratentorial anaplastic gliomas in adults: the prognostic importance of extent of resection and prior low-grade glioma. Journal of neurosurgery. 1989;71(4):487-93.

7. Dunger DB, Schwarze CP, Cooper JD, Widmer B, Neil HA, Shield J, Edge JA, Jones TW, Daneman D, Dalton RN. Can we identify adolescents at high risk for nephropathy before the development of microalbuminuria?. Diabetic medicine. 2007;24(2).

Cite this article as: Yadav $\mathrm{P}$, Rajendrasaraogi,

Chavan KN. Meshplasty: treatment for stress urinary: a prospective clinical trial.Int J Reprod Contracept Obstet Gynecol 2017;6:xxx-xx. 